\title{
The Argument from Underconsideration and Relative Realism
}

Forthcoming in International Studies in the Philosophy of Science

Moti Mizrahi

Department of Philosophy

St. John's University

8000 Utopia Parkway

Queens, NY 11439

motimizra@gmail.com

\begin{abstract}
In this paper, through a critical examination of Wray's version of the argument from underconsideration against scientific realism, I articulate a modest version of scientific realism. This modest realist position, which I call "relative realism," preserves the scientific realist's optimism about science's ability to get closer to the truth while, at the same time, taking on board the antirealist's premise that theory evaluation is comparative, and thus that there are no good reasons to think that science's best theories are close to the truth.
\end{abstract}

Keywords: antirealism; argument from underconsideration; epistemic privilege; K. Brad Wray; relative realism; scientific realism

\section{Introduction}

In the context of the scientific realism/antirealism debate, scientific realism is taken to include one or more of the following theses:

(M) The Metaphysical Thesis: The world has a definite and mind-independent structure.

(S) The Semantic Thesis: Scientific theories are truth-conditioned descriptions of their intended domain. Hence, they are capable of being true or false. The theoretical terms featuring in theories have putative factual reference. So if scientific theories are true, the unobservable entities they posit populate the world. 
(E) The Epistemic Thesis: Mature and predictively successful scientific theories are well-confirmed and approximately true. So entities posited by them, or, at any rate entities very similar to those posited, inhabit the world (Psillos 2006, 135). ${ }^{1}$

Antirealism, on the other hand,

encompasses any position that is opposed to realism along one or more of the [following] dimensions [...]: the metaphysical commitment to the existence of a mind-independent reality [i.e., (M)]; the semantic commitment to interpret theories literally or at face value [i.e., (S)]; and the epistemological commitment to regard theories as constituting knowledge of both observables and unobservables [i.e., (E)] (Chakravartty 2011).

One argument advanced by scientific antirealists as an argument against scientific realism is known as the argument from underconsideration. According to this argument, it is unlikely that our best scientific theories are true, since theory evaluation is comparative, and since scientists have no good reasons to believe they are selecting from a set of theories that contains a true theory. As Peter Lipton $(1993,89)$ points out, this argument has two premises. The first premise is the ranking premise, which states that theory testing yields comparative warrant. As Lipton $(1993,89)$ puts it: "testing enables scientists to say which of the competing theories they have generated is likeliest to be correct, but does not itself reveal how likely the likeliest theory is."

The second premise is the no-privilege premise, which states that "scientists have no reason to suppose that the process by which they generate theories for testing makes it likely that a true theory will be among those generated" (Lipton 1993, 89). From these two premises, scientific antirealists conclude that, "while the best of the generated theories may be true, scientists can never have good reason to believe this" (Lipton 1993, 89). In other words, although they might have good reasons to believe that they have selected the theory that is likeliest to be true from a set of competing theories, scientists have no good reason to believe that any of the competing theories is likely true.

A recent defender of the argument from underconsideration as an argument for antirealism is K. Brad Wray (2008). In his most recent defense of the argument, Wray (2012) himself reconstructs the argument from underconsideration as follows:

P1. In evaluating theories scientists merely rank the competitors comparatively.

\footnotetext{
${ }^{1}$ See also Psillos (1999) and Boyd (1989). Since the main argument for (E) is an argument known as the "nomiracles argument," which is an instance of Inference to the Best Explanation (IBE), any version of scientific realism that endorses (E) is sometimes referred to as "IBE realism." See, e.g., Psillos (1999) and Doppelt (2002). For critiques of the no-miracles argument, see Frost-Arnold (2010) and Mizrahi (2012a).
} 
P2. Scientists are not epistemically privileged, that is, they are not especially prone to develop theories that are true with respect to what they say about unobservable entities and processes.

C. Hence, we have little reason to believe that the theory that is judged to be superior is likely true (Wray 2012, 377).

Wray's version of the argument from underconsideration is thus aimed against the epistemic thesis of scientific realism, namely (E), which is the claim that "Mature and predictively successful scientific theories are well-confirmed and approximately true of the world" (Psillos 1999, xix). For, if Wray's argument is sound, then, contra (E), there are no good reasons to believe that successful scientific theories are approximately true.

It is important to note a crucial difference between Wray's version of the argument from underconsideration and Lipton's earlier version. Lipton's argument from underconsideration is a variation on Bas van Fraassen's "bad lot" argument. According to van Fraassen (1989, 143-144), when scientists choose between competing theories, the possibility that they are choosing from a "bad lot" cannot be ruled out a priori. Similarly, according to Lipton $(1993,89)$, there is no good reason to think that a true theory is among the competing theories from which scientists select. By contrast, Wray's version of the argument from underconsideration shifts the emphasis from theories to scientists. More explicitly, in Wray's argument quoted above, the no-privilege premise, i.e., (P2), is about scientists, not theories. That is, it says that scientists are not epistemically privileged such that they are prone to develop good theories. To illustrate, compare Wray's no-privilege premise, i.e., (P2), with Kareem Khalifa's (2010) characterization of epistemic privilege:

Privilege: A true explanation of $p$ is likely to be found among $h_{1}, \ldots, h_{\mathrm{n}}$ (Khalifa 2010, 92).

As Khalifa $(2010,92)$ points out, Lipton's no-privilege premise "is merely a denial of Privilege." In Wray's argument, however, the no-privilege premise is not merely a denial of Privilege, for it does not say that it is not the case that a true theory is likely to be found among the competing theories to be selected from, but rather that scientists are not especially prone to develop such theories. Hence, in Wray's version of the argument from underconsideration, the no-privilege premise turns from a premise about theories to a premise about scientists, and thus the argument from underconsideration turns from an argument against Inference to the Best Explanation (IBE) to an argument against scientific realism, specifically against (E). This is a crucial difference which the reader is urged to keep in mind.

In what follows, I argue that Wray's version of the argument from underconsideration fails as an argument against scientific realism. Then, from my critique of Wray's version of the argument from underconsideration, I draw a few lessons vis-à-vis the scientific 
realism/antirealism debate. In particular, I aim to show that there is a modest version of scientific realism that can acknowledge the antirealist's point about theory choice while, at the same time, still retain the realist's optimism about science's ability to get closer to the truth.

Here is how I plan to proceed. In Section 2, I argue that Wray's version of the argument from underconsideration is fallacious. I also consider several objections that scientific antirealists might make against my critique of Wray's version of the argument from underconsideration. In Section 3, I discuss an additional objection which leads to a discussion about the distinction between truth and approximate truth, and to a notion of scientific truth I call "comparative truth." Finally, in Section 4, drawing on the lessons of Section 3, I articulate a modest realist position, which I call "relative realism," and sketch an argument for this position. Finally, I explain how relative realism might be an attractive position for scientific realists and antirealists alike, and how it is different from van Fraassen's constructive empiricism.

\section{A refutation by logical analogy}

I think that the first problem with Wray's version of the argument from underconsideration quoted above is that 'privileged' is ambiguous. Recall that it is scientists that are supposed to be epistemically privileged in Wray's argument. Privilege is no longer a claim about competing theories but about scientists. In that case, talk of "being epistemically privileged" could mean that scientists do not have or do not enjoy special epistemic rights or advantages. On the other hand, it could mean that scientists are not treated with special favor. On the latter reading, (P2) would seem to be false, since scientists are treated with special favor, epistemically speaking, in most modern societies at least, insofar as "the sciences constitute the richest and most extensive body of human knowledge" (Kitcher 2002, 385), scientists are sometimes regarded as heroes (Gaukroger 2006, 30), and their work is sanctified (Gaukroger 2006, 25).

So that leaves us with the former reading, i.e., that scientists do not have or do not enjoy special epistemic rights or advantages. What sort of special rights or advantages can scientists claim to have or enjoy? They can claim to have special training and, as a result, certain skills that allow them to investigate certain domains in nature. They can claim to enjoy access to special technology, such as observation instruments and experimentation techniques, and to having the advantage of using these technologies in their investigation of nature. On this reading of "being epistemically privileged," then, why is it that scientists are not prone to develop good theories? Presumably, because they never get better at what they do. But why assume that? That is, Wray's (P2) seems to presuppose that the aforementioned aspects of theory generation, such as training, technology, and the like, do not change and that scientists never get better at what they do. But this is an unwarranted assumption.

To see why, note that Wray's version of the argument from underconsideration against scientific realism has the following logical form:

In evaluating $X \mathrm{~s}, S$ merely ranks $X$ s comparatively. 
$S$ is not privileged, i.e., $S$ is not especially prone to make good $X$ s.

$\therefore$ There is no reason to believe that the $X$ that is judged to be superior is likely good.

Now consider the following substitution instance:

P`1. In evaluating desserts, chefs merely rank the competitors comparatively.

P'2. Chefs are not "culinarily privileged," i.e., they are not especially prone to make desserts that are delicious.

C'. Hence, we have little reason to believe that the dessert that is judged to be superior is likely delicious.

Even if ( $\left(\mathrm{P}^{\wedge} 1\right)$ and $\left(\mathrm{P}^{\prime} 2\right)$ are true, I submit, $\left(\mathrm{C}^{\prime}\right)$ would still be false, since the reason to believe that the dessert that is judged to be superior is likely delicious is not that chefs are "culinarily privileged" but rather that chefs learn from experience and get better at what they do through training and practice. The problem, then, is with $\left(\mathrm{P}^{\prime} 2\right)$. As far as $\left(\mathrm{P}^{\prime} 2\right)$ is concerned, to say that chefs are "culinarily privileged" seems like a strange way of talking about the culinary arts. Chefs get better at making desserts through training and practice. If this is correct, then Wray's version of the argument from under consideration has an invalid logical form. That is, from Wray's (P1) and (P2), (C) does not follow. My diagnosis of Wray's argument is similar to the one I offered for the argument about chefs and desserts. Like chefs, who get better at making desserts through training and practice, scientists get better at developing theories through training and practice. There is nothing mysterious about "epistemic privilege" going on here.

Scientific antirealists might object to the aforementioned critique of Wray's version of the argument from underconsideration by appealing to the pessimistic induction. Indeed, Wray $(2012,380)$ writes that the "no-privilege thesis [...] asks us to acknowledge the similarities between contemporary scientists and their predecessors." He quotes Mary Hesse who argues that the support for the no-privilege premise comes from an "induction from the history of science." Wray also points out in a footnote that "this is a pessimistic induction of the sort that Laudan (1984) develops."

I have argued elsewhere that the pessimistic induction is a fallacious argument (Mizrahi $2012 b$ ). Here I would like to make a slightly different point. For scientific realists, the problem with the pessimistic induction is that it overemphasizes the similarities and underemphasizes the dissimilarities between contemporary theories and their predecessors. Similarly, as far as scientific realists are concerned, the problem with Wray's version of the argument from underconsideration is that it overemphasizes the similarities and underemphasizes the dissimilarities between contemporary scientists and their predecessors. As Alexander Bird puts it: 
The falsity of earlier theories is the very reason for developing the new ones-with a view to avoiding that falsity. It would be folly to argue that because no man has run 100 $\mathrm{m}$ in under 9.5 seconds no man ever will. On the contrary, improvements in times spur on other competitors, encourage improvements in training techniques and so forth, that make a sub 9.5 second $100 \mathrm{~m}$ quite a high probability in the near future. The analogy is imperfect, but sufficiently close to cast doubt on Laudan's pessimistic inference. Later scientific theories are not invented independently of the successes and failures of their predecessors. New theories avoid the pitfalls of their falsified predecessors and seek to incorporate their successes (Bird 2007, 80).

Likewise, Lipton $(2000,197)$ argues that we cannot infer "future theories are likely to be false" from "past theories turned out to be false" by induction because of the "Darwinian" evolution of theories. A similar point, I submit, applies to scientists as well. Contemporary scientists learn from their predecessors and they seek to avoid their predecessors' mistakes. Furthermore, contemporary scientists have access to methods and technologies that were not available to their predecessors. For scientific realists, these aspects of scientific change make a difference insofar as the ability of scientists to develop theories is concerned.

In other words, the following inductive argument is a bad inductive generalization:

Most past scientific theories turned out to be false.

Therefore, current scientific theories are probably false.

This argument is a bad inductive generalization because current theories are not quite like past theories; the sample is biased (Park 2011, 75-84). That is to say, the sample of theories in this inductive generalization from a sample is not sufficiently uniform for projecting the property of "being false" from past theories to current theories (Mizrahi 2012b). Similarly, the following inductive argument is also a bad inductive generalization:

Most past scientists had developed theories that turned out to be false.

Therefore, current scientists probably develop theories that are false.

This argument is a bad inductive generalization because current scientists are not quite like past scientists, which is why this argument an instance of biased statistics as well. That is to say, the sample of scientists in this inductive generalization from a sample is not sufficiently uniform for projecting the property of "developing false theories" from past scientists to current scientists. Current scientists are unlike past scientists in the following relevant respects: 
- Current scientists learn from their predecessors' successes and failures and seek to avoid their predecessors' mistakes. For example, scientists have learned from the mistakes of Franz Joseph Gall and others, which had led to the development of phrenology. Nowadays, scientists would not make the mistake of supposing that there is a simple connection between the relative size of different parts of a person's brain and that person's personality and character traits.

- Current scientists have access to methods and technologies that were not available to their predecessors. For example, Galileo and his contemporaries may have had telescopes but they didn't have radio telescopes, microwave anisotropy probes, and much more.

- Current scientists are able to collaborate with colleagues on increasingly large-scale, costly, and international projects. For example, it is difficult to see how a large-scale, international project like CERN's Large Hadron Collider (LHC) could have been executed even a few decades ago.

Of course, current scientists are also like past scientists in some respects. For example, both current and past scientists published their results in books and professional journals. But these respects in which they are alike are not relevant to developing theories, and hence to the inductive inference from the failures of past scientists to the claim that future scientists are likely to fail, too. This is so precisely because current scientists, and future scientists, have an expanding track record of successes and failures to draw upon and learn from.

\section{A distinction between truth and comparative truth}

Scientific antirealists might also object that my refutation by logical analogy of Wray's version of the argument from underconsideration fails because deliciousness, which is supposed to be a trait analogous to truth, is not analogues to truth at all. Deliciousness is a relative quality. For example, whatever cakes we have in a particular lot, we can always imagine being led to consider one of the cakes as delicious, especially if we never tasted a better cake before. But truth is not a relative quality. Propositions are categorically true or false, or so the objection goes.

In reply, scientific realists might concede that propositions are categorically true or false. However, they might insist that, strictly speaking, only individual propositions can be true or false (Kvanvig 2003, 191), and since theories (whatever they are) are not individual propositions, they cannot be said to be true or false. Accordingly, a theory, expressed as a set of propositions, can have true and/or false propositions as its parts. However, realists might protest, it seems that antirealists assume that even one false proposition taints a whole theory. For instance, Kitcher points out that the pessimistic induction assumes this kind of implicit holism about theories. As Philip Kitcher writes: 
We are invited to think of whole theories as the proper objects of knowledge, and thus, because the theory, taken as a whole, turns out to be false, we have the basis for a "pessimistic induction." It doesn't follow from the fact that a past theory isn't completely true that every part of that theory is false (Kitcher 2002, 388; emphasis added).

Since only individual propositions can be true or false, and since theories are not individual propositions, it follows that, strictly speaking, whole theories cannot be true or false (cf. Kitcher 1993, 118).

By way of illustration, consider the following example, which is adapted from Jarrett Leplin (1997, 133). Suppose that there is a power outage in my house. Upon looking outside my window, I see a utility truck parked nearby and some workers digging in the yard. Since I made a call to the phone company earlier about a problem with my phone line, I infer that telephone repairmen, who have responded to my earlier call, inadvertently cut the power line to my house. Unbeknownst to me, however, it is not telephone repairmen who have cut the power line but cable repairmen whom I had not expected. Now, if we take this "theory," i.e., that there is a power outage in my house because telephone repairmen have inadvertently cut the power line to my house, as a monolithic whole, then it is strictly false. However, this theory involves several claims, some are true and some are false. On the one hand, it is not the case that telephone repairmen working in the backyard have inadvertently cut the power line. On the other hand, it is true that repairmen working in the backyard have inadvertently cut the power line. I may not know the truth, the whole truth, and nothing but the truth about this state of affairs. But I do know some parts about it, and those parts are themselves true.

Consider another example from the history of science. In his An Inquiry into the Causes and Effects of the Variolae Vaccinae (1798), Edward Jenner argues that cowpox originated as grease, a disease common in horses. He claims that it was transmitted to cows when horse handlers helped with milking on occasion. In addition, Jenner $(1800,7)$ claims not only that cowpox protected against smallpox but also that "what renders the Cow Pox virus so extremely singular, is, that the person who has been thus affected is for ever after secure from the infection of the Small Pox."

Now, if we take the entire Inquiry as Jenner's "theory," then it is strictly false as a whole. He was wrong about grease being the origin of cowpox. He mistakenly took horsepox for grease, and there was no intermediate passage through cows either. Even though he got some things wrong, he was right about others. His hypothesis, properly construed, is correct. While it is not the case that vaccination provides lifelong protection, as Jenner thought, it is the case that repeated vaccination, properly done, contributes to the control of smallpox. Indeed, Jenner paved the way for this knowledge, and the know-how for selection of correct material for vaccination, with his distinction between true and spurious cowpox. Nowadays, pseudocowpox (milker's nodes) is recognized as a type of spurious cowpox (Baxby 1999). According to the World Health Organization, "Publication of the Inquiry and the subsequent promulgation by Jenner of the idea 
of vaccination with a virus other than variola virus constituted a watershed in the control of smallpox, for which he more than anyone else deserves the credit" (Fenner, et al. 1988, 264).

Another example is Paul Ehrlich's side-chain theory of antibody formation. Ehrlich proposed that harmful compounds can mimic nutrients for which cells express specific receptors. However, he considered these receptors to be on all cell types. He also did not realize that there are specialized producer cells, such as B lymphocytes. He thought of the entire spectrum of receptors as a single cell because he considered their main task as the uptake of different nutrients. These are parts of Ehrlich's side-chain theory that turned out to be incorrect. It does not follow, however, that the entire theory is wrong. Despite these errors, the theory is based on a correct principle, which is that "specific receptors on cells interact with foreign material in a highly specific way, and this triggers their increased production and release from the cell surface so that they can inactivate foreign material as antibodies" (Kaufmann 2008, 707).

If this is correct, then it seems that we should abandon talk of whole theories as being true or false. Instead, we should talk about theoretical claims as being true or false. Indeed, even antirealists seem to acknowledge this point. For instance, Wray $(2008,323)$ writes, "For the sake of clarity, let me call $H_{1}$ the Tychonic hypothesis, rather than the Tychonic theory. After all, the Tychonic theory includes an array of other claims" (emphasis added). And, more recently, Wray $(2010,6)$ writes, "But our theories, consisting of many theoretical claims, that is, a conjunction of numerous theoretical claims, are most likely false" (original emphasis).

If this is correct, then we can distinguish between truth and approximate truth. Approximate truth, which is a property of theories, is not like truth, which is a property of propositions, insofar as the former is relative, whereas the latter is categorical. Why? Because the only way to make judgments about the approximate truth of theories is by testing those theories. But antirealists would insist that theory evaluation is comparative. So when we test theories, we compare them. From a set of competing theories, if one theory $T$ passes the tests, then that is a reason to believe that $T$ is closer to that truth than its competitors. If this is correct, then to say that $T$ is approximately true is to say that $T$ is closer to the truth than its competitors.

To sum up, then, truth is a property of propositions, since only propositions can be categorically true, whereas approximate truth is a relation between theories, since a theory can be closer to the truth only relative to its competitors. Some might object, however, that theories, expressed as sets of propositions, are simply conjunctions, and conjunctions are categorically truth or false. In reply, I would argue that the truth/approximate truth distinction is analogous to the logical distinction between truth and validity. In logic courses, we teach students that deductive arguments can be valid or invalid, but not true or false. Even though, in principle, a deductive argument can be expressed as a conditional (i.e., if the premises are true, then the conclusion must be true), which is categorically true or false. In logic, we reserve the terms 'true' and 'false' to premises and conclusions, and the terms 'valid' and 'invalid' to arguments, in order to capture the difference between truth as a property of propositions and validity as a relation between propositions (more specifically, a relation between premises and a conclusion). Similarly, I submit, we should reserve the term 'true' to theoretical claims, which are individual propositions that can be categorically true or false, and the term 'approximately true' to theories, 
which is a relation between theories, even though, in principle, theories can be expressed as conjunctions.

Since I am introducing a new way of talking about approximate truth, ${ }^{2}$ and in the interest of preventing confusion, I will only talk of comparative truth rather than approximate truth. So, to say that $T_{1}$ is comparatively true is to say that $T_{1}$ is closer to the truth than competitors $T_{2}$, $T_{3}, \ldots, T_{\mathrm{n}}$, since comparative truth is a relation between theories. To address some obvious worries about this notion of comparative truth, note that, if $T_{1}$ is closer to the truth than competitors $T_{2}$ and $T_{3}, T_{2}$ can still be closer to the truth than $T_{3}$, and thus comparatively true relative to $T_{3}$. Moreover, if $T_{1}$ has no competitors, then $T_{1}$ cannot be comparatively true, since being comparatively true consists in being closer to the truth than its competitors. If there are no competitors, then a theory cannot be comparatively true. Finally, if an evaluation of competing theories $T_{1}, T_{2}$, and $T_{3}$ yields the verdict that $T_{1}$ is closer to the truth than $T_{2}$ and $T_{3}$, then $T_{1}$ is comparatively true, no matter how far from the truth $T_{1}$ is absolutely speaking. This is so because theory evaluation is comparative, as the ranking premise states. In that sense, the notion of comparative truth is an epistemic notion insofar as a theory is comparatively true based on the way it outperforms its competitors in observational and experimental testing.

\section{A modest realist position}

Scientific antirealists might also object that my refutation by logical analogy of Wray's version of the argument from underconsideration fails because Wray's argument need not presuppose that scientists never get better at what they do. That is, antirealists might object that scientists do get better at theory generation, but they never become good enough such that it is reasonable to believe that the theories they develop are likely true. It seems to me that antirealists would be correct in arguing that there are no good reasons to believe that scientists become good enough such that it is reasonable to believe that the theories they develop are likely true. For one thing, the logical space of possible theories is such that it seems rather unlikely that scientists would stumble upon those competing theories that are closest to the truth. However, I think that antirealists are wrong in concluding from this that there are no good reasons to believe that certain theories are closer to the truth than other theories. In this section, then, I articulate a modest version of scientific realism that concedes this point to antirealists. ${ }^{3}$

\footnotetext{
${ }^{2}$ As is well known, explicating the notion of approximate truth is notoriously difficult. Popper's (1972) attempt to formalize the notion of approximate truth or verisimilitude was shown to be problematic (see Miller 1974 and Tichý 1974). Other formal approaches, such as the similarity approach (see, e.g., Niiniluoto 1987, 1998) and the type hierarchy approach (see, e.g., Aronson, Harré, and Way 1994), also suffer from technical problems (see, e.g., Aronson 1990 and Psillos 1999, respectively). For these reasons, realists have tried to explicate approximate truth in non-formal, qualitative terms (see, e.g., Leplin 1981, Boyd 1990, Weston 1992, and Smith 1998). For example, it has been suggested that $T_{2}$ is more approximately true than its predecessor $T_{1}$ if $T_{1}$ can be described as a "limiting case" of $T_{2}$ (see, e.g., Post 1971; French and Kamminga 1993). But there are problems with these informal approaches as well (Chakravartty 2010).

${ }^{3}$ My attempt to articulate a modest realist position is motivated by my work on the pessimistic induction and the nomiracles argument. As I show in Mizrahi (2012a) and Mizrahi (2012b), both arguments fail. If these two arguments are the best arguments on both sides of the realism/antirealism debate, then realism and antirealism lack adequate support.
} 
I take it that the lessons to draw from Section 3 are as follows:

(1) While truth is a property of theoretical claims, comparative truth is a relation between theories, which have theoretical claims as their parts.

(2) To say that $T_{1}$ is comparatively true is to say that $T_{1}$ is closer to the truth than competitors $T_{2}, T_{3}, \ldots, T_{\mathrm{n}}$.

For lack of a better label, call the conjunction of (1) and (2) "relative realism" (RR), ${ }^{4}$ since it acknowledges the antirealist's point that theory evaluation is comparative while, at the same time, retaining the realist's optimism about science's ability to get closer to the truth. The argument for $\mathrm{RR}$, then, goes like this:

In evaluating theories, scientists rank the competitors comparatively. [the ranking premise]

If scientists rank competing theories comparatively, then scientists are justified in making comparative judgments, rather than absolute judgments (i.e., $T_{1}$ is likely true), about competing theories. [Cf. Wray 2008, 322-324]

Therefore, scientists are justified in making comparative judgments, rather than absolute judgments (i.e., $T_{1}$ is likely true), about competing theories.

To make comparative judgments about competing theories is to say that a theory is comparatively true or that it is closer to the truth than its competitors (i.e., $T_{1}$ is closer to the truth than $\left.T_{2}, T_{3}, \ldots, T_{\mathrm{n}}\right)$. The upshot of this argument, then, is that theory evaluation can give us reasons to believe that a theory is comparatively true (i.e., that $T_{1}$ is closer to the truth than $T_{2}$, $T_{3}, \ldots, T_{\mathrm{n}}$ ) but it cannot give us reasons to believe that a theory is closest to the truth (i.e., that $T_{1}$ is likely true). For example, consider the following logical space of possible theories:

$$
\begin{array}{lllllllll}
T_{1} & T_{2} & T_{3} & T_{4} & T_{5} & T_{6} & T_{7} & T_{8} & \text { TRUTH }
\end{array}
$$

\footnotetext{
${ }^{4}$ Nicholas Rescher $(1990,102)$ once used the label "relativistic realism" to refer to "a realism that is relativistic in that its insistence on the multi-faceted nature of the real means that any science will reflect its deviser's particular 'slant' on reality (in line with the investigator-characteristic modes of interaction with nature). On such a view, knowledge of reality is always (in some crucial respect) cast in terms of reference that reflect its possessor's cognitive proceedings. There is, no doubt, a mind-independent reality, but cognitive access to it is always mindconditioned."
} 
If scientists evaluate $T_{2}$ and $T_{3}$ by observational and experimental testing, they could reasonably make the comparative judgment that $T_{3}$ is closer to the truth than $T_{2}$. However, a theory can be closer to the truth relative to its competitors but still be quite far off from the truth, given the logical space of possible theories. Theory evaluation cannot tell us which theory is closest to the truth, unless we have reasons to believe that the theories we are testing are those that are closest to the truth (i.e., $T_{7}$ and $T_{8}$ ). Since we do not have reasons to believe that, however, we cannot reasonably claim that the theories we have tested are closest to the truth (i.e., likely true), although we can reasonably claim that one of them is closer to the truth than its competitors. In other words, theory evaluation can tell us which theory among competing theories is closer to the truth (e.g., that $T_{3}$ is closer to the truth than $T_{2}$ ). However, theory evaluation cannot tell us which theory among competing theories is closest to the truth.

By way of illustration, consider the following sets of competing theories:

Lot $1\left\{T_{1}, T_{2}, T_{3}, T_{4}\right\}$

Lot $2\left\{T_{5}, T_{6}, T_{7}, T_{8}\right\}$

Theory evaluation can justify the belief that $T_{4}$ is comparatively true, which is elliptical for $T_{4}$ is closer to the truth than $T_{1}, T_{2}$, and $T_{3}$. But theory evaluation cannot justify the belief that $T_{4}$ is likely true (or closest to the truth). Similarly, theory evaluation can justify the belief that $T_{8}$ is comparatively true, which is elliptical for $T_{8}$ is closer to the truth than $T_{5}, T_{6}$, and $T_{7}$. But theory evaluation cannot justify the belief that $T_{8}$ is likely true (or closest to the truth), since we do not know (or justifiably believe) if we are testing theories from Lot 1 or Lot 2 . In other words, we have no way of knowing (or justifiably believing) the position of the theories we are testing in the logical space of possible theories. ${ }^{5}$

This modest realist position, namely RR, is still robust enough, I submit, for it preserves the realist's optimism about science's ability to get closer to the truth, which is characteristic of most versions of scientific realism. In addition, RR has the added benefit of rendering Wray's version of the argument from underconsideration ineffective as an argument against scientific realism, since the relative realist need not be committed to the claim that $S$ (i.e., a scientist) is privileged in a way that allows him/her to make good (i.e., true) Xs (i.e., scientific theories), just as the food critic need not be committed to the claim that $S$ (i.e., a chef) is privileged in a way that allows him/her to make good (i.e., delicious) $X$ s (i.e., desserts). Instead, all the relative realist and the food critic need to assume is that $S$ can get better at making Xs. Indeed, the

\footnotetext{
${ }^{5}$ Theo A. F. Kuipers $(2009,221-250)$ defends a view he calls "comparative realism" (CR), whose main claim is that "truth approximation provides the default explanation and prediction of empirical and aesthetic progress." My own "relative realism" (RR) shares CR's main epistemic claim that we are only justified in making comparative judgments about the truth (or, as I call it, "comparative truth") of competing theories, not absolute judgments. As I see it, the main difference between CR and RR lies in the way they are argued for. Kuipers' argument for CR is essentially an inference to the best explanation, whereas my argument for RR is an argument from the nature of theory evaluation itself, since I don't think that one can infer realism from explanatory and/or aesthetic considerations (Mizrahi 2012a). In other words, Kuipers' CR is wedded to IBE in a way that my RR isn't.
} 
relative realist need not be committed to the claim that the $X$ (i.e., a scientific theory) that is judged to be superior is likely good (i.e., true), just as the food critic need not assume that the $X$ (i.e., a dessert) that is judged to be superior is likely good (i.e., delicious). Instead, all the relative realist and the food critic need to assume is that the $X$ that is judged to be superior is better than the other $X \mathrm{~s}$ in the set.

Despite being an essentially realist position, albeit very modest, RR might be an attractive position to antirealists as well, for it takes on board the antirealist premise that theory evaluation is comparative, i.e., the ranking premise. However, unlike antirealists who take the ranking premise as a reason to be skeptical about judgments concerning the truth of theories, relative realists take it as a reason to be skeptical only about absolute judgments, but not comparative judgments, about the truth of scientific theories.

As a further bonus to antirealists, RR seems to mesh nicely with the antirealist's favorite explanation for the success of science, namely, van Fraassen's selectionist explanation. (See also Wray 2007 and 2010.) According to van Fraassen's (1980, 39-40) selectionist explanation for the success of science, the predictive success of mature and well-confirmed scientific theories can be explained by positing a selection process for scientific theories that is similar to natural selection. But the products of natural selection are not optimizations. Rather, natural selection is a "satisficing" process, not an optimizing process (Simon 1979, 3). In that case, the selection process for scientific theories should be a satisficing process as well, which means that it is the kind of process that does not bring about optimal results but rather results that meet a certain threshold. That threshold requires that new products (e.g., theories or scientists) simply be better than previous ones, even though those new products could still be very far from optimal (e.g., true or epistemically privileged). That is to say, a selection process for scientists, if there is such a thing, is probably a satisficing process as well, which means that it is the kind of process that does not bring about optimal results but rather results that meet a certain threshold. That threshold requires that new products (i.e., scientists) simply be better than previous ones, even though those new products could still be very far from optimal (i.e., epistemically privileged scientists).

Despite being compatible with an antirealist explanation for the success of science, RR is still different from van Fraassen' antirealist position, namely, constructive empiricism. The most important difference is the following:

(J) $T_{1}$ is closer to the truth than its competitors $T_{2}$ and $T_{3}$.

For a relative realist, a comparative judgment like $(\mathrm{J})$ can be justified on the basis of theory evaluation. A constructive empiricist, on the other hand, would recommend agnosticism with respect to comparative judgments like $(\mathrm{J})$. For a constructive empiricist, $(\mathrm{J})$ sabotages its own possibility of vindication (van Fraassen 1989, 157), since ( $\mathrm{J}$ ) is a judgment about theories that involve unobservables, which makes "vindication [...] a priori precluded" (van Fraassen 1983, 297). ${ }^{6}$ This is not to say that, for a constructive empiricist, (J) cannot be true. As van Fraassen writes $(1989,177)$, "The truth of a judgment (for example, about unobservable entities) might

\footnotetext{
${ }^{6}$ There is some debate as to whether, and to what extent, van Fraassen's constructive empiricism is informed by his voluntarist epistemology. See, e.g., Psillos (2007). Cf. Dicken (2009).
} 
not be decidable. Yet, a certain judgment may be true 'if only by accident'." Accordingly, although (J) may be true "if only by accident," it is not decidable, and hence the constructive empiricist would recommend suspending judgment about (J). On the other hand, as far as the relative realist is concerned, $(\mathrm{J})$ can warrant belief on the basis of theory evaluation.

\section{Conclusion}

In this paper, I have argued that Wray's version of the argument from underconsideration against scientific realism is fallacious. This critique of Wray's argument allowed me to distinguish between truth and comparative truth and, in turn, to articulate a modest realist position, which I have called "relative realism." The virtue of relative realism is that it preserves the scientific realist's optimism about science's ability to get closer to the truth while, at the same time, taking on board the antirealist's premise that theory evaluation is comparative. As an added bonus to antirealists, relative realism is even compatible with an antirealist, selectionist explanation for the success of science.

\section{Acknowledgments}

An earlier version of this paper was presented at the $23^{\text {rd }}$ Biennial Meeting of the Philosophy of Science Association, San Diego, 15-17 November 2012. I would like to thank the PSA and the History of Science Society for a generous travel grant. I would also like to thank Paul Hoyningen-Huene and P. Kyle Stanford for their useful feedback on my talk. I am very grateful to two anonymous referees for International Studies in the Philosophy of Science for helpful comments on an earlier draft. Finally, special thanks are due to the editor, James McAllister.

\section{References}

Aronson, J. L. (1990). Verisimilitude and Type Hierarchies. Philosophical Topics, 18, 5-28. Aronson, J. L., Harré, R. and Way, E. C. (1994) Realism Rescued: How Scientific Progress is Possible. London: Duckworth.

Baxby, D. (1999). Edward Jenner's Inquiry: A Bicentenary Analysis. Vaccine, 17, 301-307. Bird, A. (2007). What Is Scientific Progress? Noûs, 41, 64-89.

Boyd, R. (1983). The Current Status of the Issue of Scientific Realism. Erkenntnis, 19, 45-90.

Boyd, R. (1990). Realism, Approximate Truth and Philosophical Method. In C. W. Savage (ed.), Scientific Theories, Minnesota Studies in the Philosophy of Science, vol. 14 (pp. 355391). Minneapolis: University of Minnesota Press.

Chakravartty, A. (2010). Truth and Representation in Science: Two Inspirations from Art. In R. Frigg and M. Hunter (eds.), Beyond Mimesis and Convention: Representation in Art and Science, Boston Studies in the Philosophy of Science (pp. 33-50). Dordrecht: Springer.

Chakravartty, A. (2011). Scientific Realism. In E. N. Zalta (ed.), The Stanford Encyclopedia of Philosophy (Summer 2011 Edition). http://plato.stanford.edu/archives/sum2011/entries/scientific-realism. 
Dicken, P. (2009). Constructive Empiricism and the Vices of Voluntarism. International Journal of Philosophical Studies, 17, 189-201.

Doppelt, G. (2002). Review of Scientific Realism: How Science Tracks Truth by Stathis Psillos. The Philosophical Review, 111, 142-147.

Fenner, F., Henderson, D. A., Arita, I., Ježek, Z., and Ladnyi. I. D. (1988). Smallpox and Its Eradication. Geneva: World Health Organization. Available at http://apps.who.int/iris/bitstream/10665/39485/1/9241561106.pdf.

French, S. and Kamminga, H. (eds.). (1993). Correspondence, Invariance and Heuristics. Dordrecht: Kluwer.

Frost-Arnold, G. (2010). The No-Miracles Argument for Realism: Inference to an Unacceptable Explanation. Philosophy of Science, 77, 35-58.

Gaukroger, S. (2006). The Emergence of a Scientific Culture: Science and the Shaping of Modernity 1210-1685. New York: Oxford University Press.

Jenner, E. (1800). An inquiry into the causes and effects of the variolae vaccinae: a disease discovered in some of the western courtiers of England, particularly Gloucestershire, and known by the name of the Cow Pox. 2 ed: Printed for the Author by Sampson Low.

Kaufmann, S. H. E. (2008). Immunology's Foundation: The 100-year Anniversary of the Nobel Prize to Paul Ehrlich and Elie Metchnikoff. Nature Immunology, 9, 705-712.

Khalifa, K. (2010). Default Privilege and Bad Lots: Underconsideration and Explanatory Inference. International Studies in the Philosophy of Science, 24, 91-105.

Kitcher, P. (1993). The Advancement of Science: Science without Legend, Objectivity without Illusions. New York: Oxford University Press.

Kitcher, P. (2002). Scientific Knowledge. In P. K. Moser (ed.), The Oxford Handbook of Epistemology (pp. 385-407). New York: Oxford University Press.

Kuipers, A. F. T. (2009). Comparative Realism as the Best Response to Antirealism. In C. Glymour, W. Wei, and Dag Westerstahl (Eds.), Logic, Methodology and Philosophy of Science: Proceedings of the Thirteenth International Congress (pp. 221-250). London: King's College Publications.

Kvanvig, J. (2003). The Value of Knowledge and the Pursuit of Understanding. New York: Cambridge University Press.

Laudan, L. (1981). A Confutation of Convergent Realism. Philosophy of Science, 48, 19-49.

Laudan, L. (1984). Science and Values: The Aims of Science and their Role in Scientific Debate, Pittsburgh Series in Philosophy and History of Science. Berkeley: University of California Press.

Leplin, J. (1981). Truth and Scientific Progress. Studies in History and Philosophy of Science, 12, 269-291.

Leplin, J. (1997). A Novel Defense of Scientific Realism. New York: Oxford University Press.

Lipton, P. (1993). Is the Best Good Enough? Proceedings of the Aristotelian Society, 93, 89-104.

Lipton, P. (2000). Tracking Track Records. Proceedings of the Aristotelian Society, 74, 179-205.

Lyons, T. D. (2006). Scientific Realism and the Stratagema de Divide et Impera. British Journal for the Philosophy of Science, 57, 537-560.

Miller, D. (1974). Popper's Qualitative Theory of Verisimilitude. British Journal for the Philosophy of Science, 25, 166-177.

Mizrahi, M. (2012a). Why the Ultimate Argument for Scientific Realism Ultimately Fails. Studies in History and Philosophy of Science, 43, 132-138. 
Mizrahi, M. (2012b). The Pessimistic Induction: A Bad Argument Gone Too Far. Synthese. DOI 10.1007/s11229-012-0138-3.

Park, S. (2011). A Confutation of the Pessimistic Induction. Journal of General Philosophy of Science, 42, 75-84.

Popper, K. R. (1972). Conjectures and Refutations: The Growth of Knowledge. $4^{\text {th }}$ Ed. London: Routledge.

Post, H. R. (1971). Correspondence, Invariance and Heuristics: In Praise of Conservative Induction. Studies in History and Philosophy of Science, 2, 213-255.

Psillos, S. (1999). Scientific Realism: How Science Tracks Truth. London: Routledge.

Psillos, S. (2006). Thinking about the Ultimate Argument for Realism. In C. Cheyne and J. Worrall (eds.), Rationality \& Reality: Essays in Honour of Alan Musgrave (pp. 133-156). Dordrecht: Springer.

Psillos, S. (2007). Putting a Bridle on Irrationality: An Appraisal of van Fraassen's New Epistemology. In B. Monton (ed.), Images of Empiricism: Essays on Science and Stances with a Reply by Bas C. van Fraassen (pp. 134-164). New York: Oxford University Press.

Rescher, N. (1990). A Useful Inheritance: Evolutionary Aspects of the Theory of Knowledge. Savage, MD: Rowman \& Littlefield Publishers, Inc.

Simon, H. A. (1979). Models of Thought. New Haven: Yale University Press.

Smith, P. (1998). Approximate Truth and Dynamical Theories. British Journal for the Philosophy of Science, 49, 253-277.

Tichý, P. (1974). On Popper's Definitions of Verisimilitude. British Journal for the Philosophy of Science, 25, 155-160.

Van Fraassen, B. C. (1980). The Scientific Image. New York: Oxford University Press.

Van Fraassen, B. C. (1983). Calibration: A Frequency Justification for Personal Probability. In R. S. Cohen and L. Laudan (eds.), Physics, Philosophy and Psychoanalysis (pp. 295-319). Dordrecht: D. Reidel Publishing Co.

Van Fraassen, B. C. (1989). Laws and Symmetry. Oxford: Clarendon Press.

Van Fraassen, B. C. (1998). The Agnostic Subtly Probabilified. Analysis, 58, 212-220.

Van Fraassen, B. C. (2010). Reply to Contessa, Ghins, and Healey. Analysis, 70, 547-556.

Weston, T. (1992). Approximate Truth and Scientific Realism. Philosophy of Science, 59, 53-74.

Wray, K. B. (2007). A Selectionist Explanation for the Success and Failures of Science. Erkenntnis, 67, 81-89.

Wray, K. B. (2008). The Argument from Underconsideration as Grounds for Anti-realism: A Defence. International Studies in the Philosophy of Science, 22, 317-326.

Wray, K. B. (2010). Selection and Predictive Success. Erkenntnis, 72, 365-377.

Wray, K. B. (2012). Epistemic Privilege and the Success of Science. Noûs, 46, 375-385. 